University of Warwick institutional repository: http://go.warwick.ac.uk/wrap

This paper is made available online in accordance with publisher policies. Please scroll down to view the document itself. Please refer to the repository record for this item and our policy information available from the repository home page for further information.

To see the final version of this paper please visit the publisher's website. Access to the published version may require a subscription.

Author(s): Ateweberhan, M., McClanahan, T. R., Graham, N. A. J. and Sheppard, C. R. C.

Article Title: Episodic heterogeneous decline and recovery of coral cover in the Indian Ocean

Year of publication: 2011

Link to published article:

http://dx.doi.org/10.1007/s00338-011-0775-x

Publisher statement: The original publication is available at www.springerlink.com 


\section{Episodic heterogeneous decline and recovery of coral cover in the Indian Ocean}

M. Ateweberhan ${ }^{1,2 *}$, T. R. McClanahan ${ }^{2,3}$, N. A. J. Graham ${ }^{4}$, C. R. C. Sheppard ${ }^{1}$

1. Biological Sciences, University of Warwick, Coventry, CV4 7AL, UK

2. Coral Reef Conservation Project, P.O. Box 99470, Mombasa, Kenya

3. Wildlife Conservation Society, Marine Program, Bronx, New York 10430, USA

4. ARC Centre of Excellence for Coral Reef Studies, James Cook University, Townsville, QLD 4811, Australia

Running title: Indian Ocean coral cover trends

Reviewed submission for Coral Reefs: February 2011

*Address of correspondence: m.ateweberhan@warwick.ac.uk, mateweberhan@wcs.org 


\section{Abstract}

Long term changes in coral cover for the Caribbean and the Pacific/Southeast Asia regions (PSEA) have proven extremely useful in assessing the main drivers, magnitude and time scales of change. The one major coral reef region where such assessments have not been made is the Indian Ocean (IO). Here we compiled coral cover survey data from across the IO into a database of $\sim 2000$ surveys from 366 coral reef sites collected between 1977 and 2005. The compilation shows that the 1998 mass coral bleaching event was the single most important and widespread factor influencing the change in coral cover across the region. The trend in coral cover followed a step-type function driven by the 1998 period, which differs from findings in the Caribbean and the PSEA regions where declines have been more continuous and mostly began in the 1980s. Significant regional variation was observed, with most heterogeneity occurring during and after 1998. There was a significant relationship between cover and longitude for all periods, but the relationship became stronger in the period immediately after 1998. Before 1998, highest coral cover was observed in the central IO region, while this changed to the eastern region after 1998. Coral cover and latitude displayed a significant U-shaped relationship immediately after 1998, due to a large decrease in cover in the northern-central regions. Post-1998 coral cover was directly correlated to the impact of the disturbance; areas with the lowest mortality having the highest cover with India-Sri Lanka being an outlier due to its exceptionally high recovery. In 1998, reefs within Marine Protected Areas (MPAs) were more heavily impacted than unmanaged reefs, losing significantly greater total cover. MPA recovery was greater so that no differences were observed by 2001-2005. This study indicates that the regional patterns in coral cover distribution in the IO is driven mainly by episodic and acute environmental stress. 
Keywords: ENSO, climatic disturbance, climate change impact, coral bleaching, coral reef management, ecological vulnerability, marine protected areas (MPAs), marine reserves, recovery, regional variation 


\section{Introduction}

Coral reefs are experiencing the effects of multiple stresses that are mainly associated with excessive resource extraction, eutrophication, and coastal development. Climate change driven increase in seawater temperature, intensity and frequency of extreme thermal events and increase in ocean acidification have added to the above and are becoming a major threat to coral reefs (HoeghGuldberg 1999; Nyström et al. 2000; McClanahan et al. 2002; Hughes et al. 2003; Sheppard 2003; Bellwood et al. 2004; HoeghGuldberg et al. 2007). Indeed, one-third of reef building coral species and one-third of coral reef fish species are considered threatened by global change (Carpenter et al. 2008; Graham et al. 2011). In many regions of the world, the decline of corals has resulted in shifts in dominance from hard corals to macroalgae and other sessile invertebrate dominated benthic functional groups (Done 1992;

Nyström et al. 2000; Mumby et al. 2007; Norström et al. 2008; Hughes et al. 2010; Schutte et al. 2010). Corals are the main framework builders of reefs and reductions in coral abundance and associated changes in community structure results in declining biodiversity, ecological services, and fisheries production (Bell and Galzin 1984; Edinger et al. 1998; Jones et al. 2004; Garpe et al. 2006; Graham et al. 2006, 2007, 2008; Pratchett et al. 2008).

Coral abundance is commonly described by its cover, often relative to the total area covered by other benthic biota. Cover is an important measure because space regulates benthic interactions on coral reefs (Hastings 1980), including competition for resources

(Hughes et al. 1992), and changes in this parameter are commonly used in investigating effects of environmental gradients (Sandin et 
al. 2008). While we recognize there are limitations, such as unmeasured changes in species composition, changes in provision of 3dimensional space with increasing cover, and changes in ecological processes (Hughes et al. 2010), coral cover can be a useful indicator of responses to large-scale disturbances, often linked to multiple stress factors that are not taxa specific (Gardner et al. 2003; Bruno and Selig 2007). Corals are major contributors to calcification and play an important role as ecological facilitators, and declines in coral cover will have significant ecological implications (Graham et al. 2006; Idjadi and Edmunds 2006). Coral cover is therefore commonly used to describe the overall health and general status of a reef in relation to shifting dominance, ecological processes, and economic services provided to human communities.

Recent studies in the Caribbean, Pacific/Southeast Asia (PSEA) regions have compiled coral cover data since the 1970s and found significant long-term, region-wide declines in coral cover along with shifts in benthic cover dominance (Gardner et al. 2003; Bruno and Selig 2007). The Caribbean study (Gardner et al. 2003) showed a region-wide steady decline due to the combined effect of multiple stressors, which included overfishing, eutrophication, coastal development, coral diseases and coral bleaching. Later studies of Caribbean coral cover data have suggested that white-band disease in the early 1980s may have been one of the strongest sources of coral mortality (Aronson and Precht 2006; Schutte et al. 2010), however hurricane activity has also been implicated (Gardner et al. 2005). Bruno and Selig (2007) studied changes in cover in the PSEA region which also indicated a steady and uniform decline, irrespective of management, that is most likely associated with a steady increase in chronic stresses and bleaching disturbance (Bruno 
and Selig 2007). A Bayesian analysis of the influence of MPA closures on coral cover change, showed a strong impact of the 1998 ENSO for the PSEA, whereby faster rates of coral cover increase in MPAs were no longer observed (Selig and Bruno 2010).

The Indian Ocean Region (IO) remains the one major global coral reef region where little is known about the timing, rate or spatial variability in coral cover change over the past few decades. Several time-restricted studies have been conducted recently, but these focused mostly on the response of reefs to the 1998 temperature anomaly and recovery from its impact (McClanahan et al. 2007a; Baker et al. 2008; Graham et al. 2008; Ateweberhan and McClanahan 2010). There are currently no large-scale studies of the IO, comparing regions and considering long-term changes that may have occurred considerably before 1998. This study fills this gap by compiling multiple sources of coral cover data since the first published estimates of coral cover were made. The analyses specifically aim to 1) investigate long-term patterns of coral cover across the IO, 2) quantify regional variations in coral cover through time, and 3) identify the main sources of variation in coral cover change. In addition to filling the information gap in the global status and regional trends of coral cover on coral reefs, the study has implications for predicting vulnerability of IO reefs to future climate change and will also help prioritize management requirements.

\section{Materials and methods}

Study area and data collection 
The study area included all the major coral reef regions in the Western Indian Ocean (WIO), which, traditionally refers to the region west of the $90^{\circ} \mathrm{E}$ meridian and locations in Southeast Asia (SE Asia) and Western Australia that were not included in the regional analysis of Bruno and Selig (2007). The study area was classified into 11 regions based on traditional classifications used in the region and experience of the investigators. However, the Bay of Bengal was not included in the periodic comparisons because of the low suitability of the region for reef development and the resulting paucity in data (Fig. 1; Table 1).

The study included four main data sources: 1) peer-reviewed publications, 2) gray literature, 3) Reef Check surveys (http://www.Reefcheck.org), and 4) regional monitoring programs (Table 1). First, the libraries of the Wildlife Conservation Society (WCS), Kenya and the Biological Sciences Department, Warwick University were thoroughly searched for literature on IO coral reefs. From all identified publications and reports coral cover data and other benthic cover data were extracted. This included all the recent reports by the global coral reef monitoring network (GCRMN) and Coral Reef Degradation in the Indian Ocean (CORDIO) ${ }^{1}$.

Secondly, we searched Google Scholar by entering the words 'coral' followed by the name of a country (e.g., Kenya), a region (e.g., East Africa) or a reef (e.g., Malindi) within the IO. Thirdly, we obtained Excel spreadsheet cover data from Reef Check for the regions of the IO defined above. Finally, e-mails requesting cover data were dispatched to individuals and institutions that are, or have been, actively monitoring coral reefs in the region. A positive response was received from several individuals/institutions, contributing a

\footnotetext{
${ }^{1}$ CORDIO now stands for Coastal Oceans Research and Development in the Indian Ocean,
} 
small portion of the total database (Table 1). Other unpublished survey data came mainly from the authors. Most field sampling was based on haphazard or permanent Line Intercept Transects (LIT).

The scale of the study necessitates utilization of data from several sources that were collected using different techniques that could have some shortcomings (Hughes et al. 2010). Particularly, there are concerns that data collected by non-professionals (e.g., Reef Check) could be one of the main sources of error in regional analysis (Bruno and Selig 2007). Reef Check tries to minimize this by ensuring that volunteers involved in the program are trained and supervised by professional scientists. Coral cover is a fairly simplistic measure and data collected by different observers and methods have been shown to yield similar results (Carleton and Done 1995; Wilson et al. 2007). Reef Check data have successfully been used in regional analysis of coral cover (e.g., Bruno and Selig 2007). Nevertheless, we compared difference in data from the four sources (Table 1) using ANOVA for 2005, the year with the largest Reef Check data. Overall, there was a significant difference $(F=11.66 ; \mathrm{p}<0.0001)$ and Reef Check data had greater mean value $(38.61 \pm$ 1.89 ) than the remaining data types (gray literature: $27.72 \pm 2.60$; peer reviewed literature: $25.43 \pm 3.23$; survey: $20.83 \pm 2.69$ ). 
To account for a possible regional difference, we also compared data for the EIO, the region with the greatest Reef Check samples. Again, cover was higher for Reef Check data than those from gray literature $(F=11.36 ; p=0.002$; Reef Check: $49.71 \pm 3.37$; gray literature: $32.17 \pm 3.23$ ).

We also tested for the confounding effects of depth on our results by including depth in the analysis of 639 samples where information on depth was available, Regression analysis showed a weak decreasing linear relationship with depth $\left(\mathrm{R}_{\text {adj }}^{2}=0.006 ; \mathrm{F}=5.63 ; \mathrm{p}=\right.$ 0.02). When we included region, we obtained a slightly improved prediction $\left(\mathrm{R}^{2}\right.$ adj $\left.=0.14 ; \mathrm{F}=10.92 ; \mathrm{p}<0.0001\right)$, with significant effects of region $(\mathrm{F}=18.14 ; \mathrm{p}<0.0001)$ and region-depth interaction $(\mathrm{F}=3.45 ; 0.0006)$. Inclusion of the time period also gave a weak prediction $\left(R_{\text {adj }}^{2}=0.02 ; F=5.02 ; p<0.0001\right)$, significant effects for period $(F=9.02 ; p<0.0001)$ and depth $(F=5.26 ; p<0.02)$. There was no significant depth-period interaction $(\mathrm{F}=2.20 ; \mathrm{p}=0.09)$. We were not able to conduct a three-way analysis due to loss of degrees of freedom. Despite the significant effects, depth related influence was low in comparison to those of region and period (whole model: $\mathrm{R}_{\text {adj }}^{2}=0.30 ; \mathrm{F}=23.05 ; \mathrm{p}<0.0001$; region: $\mathrm{F}=11.20 ; \mathrm{p}<0.0001$; period: $\mathrm{F}=12.77 ; \mathrm{p}<0.0001$; region-period interaction: $\mathrm{F}=11.06 ; \mathrm{p}<0.0001$; also see Table 2). 
The resulting database contained cover data of 1,997 quantitative cover surveys for 366 coral reef sites collected between 1958 and 2005 (Table 1). A 'site' generally represented an average of many data points (transects and locations). Of these, 40 comprised areas with fisheries closures, such as reserves and no take areas. Although most of the surveyed reefs were open to fishing, we used data only for those reefs that were specifically indicated as 'fished' and 'fisheries closures'. Data were collected mostly from shallow reef zones $(<10 \mathrm{~m})$.

Corals of the IO, particularly the western and central regions, suffered the highest mortalities globally during the 1998 climatic disturbance. By taking 1998 as a reference point, we compared coral cover between four time periods: 1977-1993 (period 1), 19941997 (period 2), 1999-2000 (period 3) and 2001-2005 (period 4). Period 1 was well before the 1998 climatic disturbance but also was the period when regional cover data were generally sparse. Period 2 represented a time of significant increase in regional survey data, as well as being the period just before the 1998 climatic disturbance. Period 3 immediately followed the 1998 disturbance when marked coral decline was seen together with a significant shift in community structure for many of the region's reefs. Data from 1998 were excluded from this period because it was often not clear whether they were sampled before, during or after the coral bleaching event, and it would also be difficult to ascertain how much of the measured cover was living just after the disturbance. Period 4 represented post-bleaching phases for many of the reefs that were affected in period 3. Coral reef monitoring intensified post-1998 
because of the widespread bleaching mortality in 1998 (Lindén and Sporrong 1999; Wilkinson 1999, 2002, 2004; Souter et al. 2000; Linden et al. 2002; Souter and Linden 2005), which resulted in a dramatic increase in post-1998 coral cover samples (Table 1).

\section{Data analysis}

Cover frequency distributions were determined for each year and for the 4 periods for the whole region. Distributions were also determined for each of the ten regions in the IO (Table 1). In analyses of the ten regions, various data were excluded for different reasons. Years and regions that had low sample sizes $(\mathrm{N}<20)$ were excluded, and data from before 1977 were excluded as they were mostly from one area only, Rashdu Atoll, Central Maldives, CIOI; Table 1 (Scheer 1974). Years before 1994 were not included in the analysis of individual years due to low sample sizes $(\mathrm{N}=1-18)$. However, we pooled pre-1994 data into three time periods (1977-

1983; 1984-1989; 1991-1993) that ensured enough regional representation. Years after 1993 had large sample sizes, ranging from 37 to 308 .

Temporal variation in cover between years for the whole region was tested with Repeated Measures ANOVA (RMA) on square-root transformed data. Temporal variation between periods and its interactions with region, latitude and longitude were tested with multilevel RMA for the four periods. Subsequently, differences in mean cover between years and periods for the whole region and between periods within each region and between regions for each period were compared with Kruskal-Wallis $\chi^{2}$ test because assumptions for 
normality of data (Shapiro-Wilk W) and homogeneity of variance (Levene's test) were not met in most cases. In addition, differences in the shapes of the frequency distribution between regions for each period and among periods within a region were compared with the Kolmogorov-Smirnov $\mathrm{Z}$ test. We also tested for regional change in coral cover correlated with latitude/longitude using regression analysis.

Management was not included in the RMA due to low sample size in some of the regions. Thus, changes in cover between MPAs and unmanaged reefs were compared with the Kruskal-Wallis $\chi^{2}$ test for sites where information on management was stated in the text of the evaluated documents.

\section{Results}

Region-wide coral cover showed significant temporal variation (Fig. 2a,b). Yearly comparisons (1994-2005) indicated that regional cover was lowest in 1999 and highest in 1995-1997 (Fig. 2a; Kruskal-Wallis $\chi^{2}=218.6$; p 0.0001). Cover data in all periods were significantly different from the normal distribution (Shapiro-Wilk W test; $p<0.001$ in all periods) with period 3 (1999-2000) having the highest deviance from normality (Shapiro-Wilk W $=0.92 ; \mathrm{p}<0.0001$ ). 
Analysis of the 4 time periods for the regional cover data of the whole region indicated significant temporal variation and significant region-period, latitude-period and longitude-period interactions (Table 2). Period 3 had the lowest cover, period 1 and 2 the highest and period 4 intermediate cover (Fig. 2b; Fig. 3; Table 3B; Electronic Supplemental Material, ESM Appendix 1; Kruskal-Wallis $\chi^{2}=$ 185; $\mathrm{p}<0.0001)$. The difference was strongest between period 2 and 3 . Considering the smaller sample size in Period 1 , the results in that period should be interpreted with caution and the focus is mainly on the remaining 3 periods. The mean coral cover across the entire region declined $17.4 \%$ from $39.7 \%$ (period 2) to $22.3 \%$ (period 3) as a result of the 1998 climatic disturbance, representing a relative decline in coral cover of $44 \%$. By period 4 , mean coral cover had increased by $8.4 \%$ to $30.7 \%$, which was $72.6 \%$ of predisturbance levels (Table 2).

The distribution properties of the coral cover reflect the change in cover before and after 1998 (Fig. 2; Table 3A). Region wide change in mean cover was accompanied by a marked shift in the median values, skewness and kurtosis (Table 3A). Cover distributions in periods 1 and 2 were similar and became increasingly right skewed due to the large increase in the proportion of reefs with low cover in the period immediately after 1998. The increase in the mean and median values in period 4 emerging from the post bleaching recovery indicates a near return of the skewness to the pre 1998 level, while the kurtosis indicated a widening distribution (Table 3A). 
Regional analyses by time period also indicated a strong difference between period 3 (and to some extent between period 4) with the other periods (Table 3B; ESM Appendix 1). There was a significant difference between periods 2 and 3, except in the southwestern Indian Ocean Islands region (SWIOI). There were no difference between periods 2 and 4 in India-Sri Lanka (IND-SRI) and the Red Sea and Gulf of Aden (RS-GA). Coral cover was not different between periods 3 and 4 in the eastern region (EIO), SWIOI and Mozambique-South Africa (MOZ-SAF),

Reefs in central western Indian Ocean Islands (CIOI), the Arabian/Persian Gulf (GULF) and IND-SRI had the highest absolute decline in mean cover across 1998 (32-35\%) followed by East Africa (EAFR; 15\%). EIO, RS-GA and SWIOI had lower declines (4.0-8.7\%) while MOZ-SAF had a marginal increase in cover (1\%). A scatter plot of cover between periods 3 and 4 showed a positive relationship indicating that the cover in period 4 reflected the impact of the 1998 disturbance (Fig. 4; Table 3). IND-SRI was an outlier in this relationship due to its exceptionally high recovery (Fig. 4; Table 3).

By sub-region comparison for each period showed strong regional differences mainly in periods 3 and 4 (Fig. 3; Table 2B; ESM Appendix 2). The differences reflected the strong spatial variation in the impact of the 1998 disturbance. Of particular interest were comparisons of the IND-SRI and GULF regions with other regions where differences were stronger in period 3 but less so in period 4. Nonetheless, difference between these and the other most impacted reefs (CIOI) showed the opposite pattern, differences growing 
stronger from period 3 to period 4 due to different recovery rates. Differences between CIOI and the reefs that were less impacted in 1998 remained strong between periods 3 and 4 due to low recovery in CIOI.

Despite the significant recovery in period 4, coral cover reflected the impact of the 1998 disturbance as indicated by the significant linear relationship between cover in period 3 and $4\left(R^{2}=0.66\right.$; ANOVA F $\left.=9.55 ; p=0.027\right)$. India-Sri Lanka was an outlier from the relationship due to its fast recovery (Fig. 4; Including IND-SRI: $\mathrm{R}^{2}=0.36$; ANOVA F = 3.30; $\mathrm{p}=0.12$ ).

There was a significant relationship between cover and latitude only in period 3, immediately after the 1998 climatic disturbance (Fig. 5; Table 4A). The best fit was for a U-shaped relationship with the lowest coral cover between $5^{\circ} \mathrm{S}$ and $15^{\circ} \mathrm{N}$ but also marked by strong variation. Cover showed a significant relationship with a $2^{\text {nd }}$ degree polynomial function with longitude in all four periods (Fig. 5; Table 4B) but the curve shapes in the pre and post 1998 comparison were reversed. In periods 1 and 2 the best fit was an inverted $\mathrm{U}$-shaped curve with highest cover at $60-80^{\circ} \mathrm{E}$ while in periods 3 and 4 the relationship was represented by a U-shaped curve with sites $60-80^{\circ} \mathrm{E}$ showing the lowest cover. The relationship was stronger post than pre 1998 (Table 4B).

Comparison between areas with fisheries closures and fished reefs showed that the impact of the 1998 climatic disturbance varied by management type (Fig. 6). Areas closed to fishing had a higher coral cover than fished reefs in the periods before 1998 (period 1: 
Kruskal-Wallis $\chi^{2}=8.75 ; \mathrm{p}=0.003$; period 2: Kruskal-Wallis $\chi^{2}=9.71 ; \mathrm{p}=0.001$ ). This pattern was reversed after 1998 because of the greater loss of coral cover in areas closed to fishing (Kruskal-Wallis $\chi^{2}=6.64 ; p=0.01$ ). There was no significant difference in cover between fisheries closures and non-managed reefs in period 4 (Kruskal-Wallis $\chi^{2}=0.21 ; p=0.65$ ).

\section{Discussion}

The results of this study indicate that the 1998 temperature anomaly was the single most important factor influencing regional change in coral cover in the Indian Ocean (IO). This differs from the Caribbean (Gardner et al. 2003) and the Pacific/SE Asia regions (PSEA) (Bruno and Selig 2007) where there was a more continuous decline in regional coral cover that started in the early 1980s. A reanalysis of Caribbean data has indicated the main decline in the 1980's was either due to white-band disease and subsequent bleaching impacts (Aronson and Precht 2006; Schutte et al. 2010), or high hurricane activity (Gardner et al. 2005). Multiple, site specific, causes are also highly likely (Hughes et al. 2010). The PSEA study also emphasized the impact of multi-stress factors but had a major focus on recent bleaching events. Gardner et al. (2003) indicated that coral cover in the wider Caribbean declined from 50\% to $10 \%$ in just three decades, giving an estimated annual decline of $1.5 \%$ which is larger than the $1 \%$ estimated annual decline for the Pacific Southeast Asia (PSEA; Bruno and Selig 2007). In both regions, the greatest decline occurred in the 1980s. Data from the Indian Ocean (IO) are not available to estimate a reliable rate of change during that period. However, coral cover in 1997 (39.6\%), the year with the 
largest sample size $(\mathrm{N}=308)$ and the greatest regional representation was not significantly different from the aggregate pre 1997 cover.

Baseline IO coral cover values are difficult to estimate given the few field samples, lack of data on coral cover itself, and data on the environmental conditions at the times of measurement. Bruno and Selig (2007) suggest a cover of 50\% for reefs with low anthropogenic disturbance based on the trend in coral cover decline in the Caribbean and PSEA and some of the healthiest reefs in the PSEA. While this is debatable, it does coincide with early Caribbean estimates (Gardner et al. 2003; Schutte et al. 2010), and is only slightly greater than the average $40 \%$ cover on IO reefs before 1998. Consequently, prior to 1998, IO reefs could be considered to be in a relatively undisturbed state by this metric.

The lowest cover in the IO post 1998 is similar to the $22.1 \%$ cover recorded on the last date of the PSEA survey in 2003 (Bruno and Selig 2007; Table 3). Despite the large variation in the recovery rates of reefs in the IO after 1998, the mean coral cover for the same year (2003) was $8 \%$ higher than reefs in the PSEA and 20\% higher than reported for the Caribbean (10\%) by Gardner et al. (2003). The increased post-bleaching recovery observed in this study was different from Selig and Bruno's (2010) latest model-based prediction that shows no significant post bleaching recovery. The high initial coral cover and the fast post 1998 recovery suggest that IO reefs are probably under less pressure from other stress factors that caused major declines and no recovery in cover in the 
Caribbean and the rest of the Indo-Pacific, notably coral diseases and mass predation by crown of thorns starfish (Gardner et al. 2003; Bruno and Selig 2007; Aronson and Precht 2006; Schutte et al. 2010; Sweatman et al. 2011). The importance of other stressors in the IO may vary, but seem to be overshadowed by the effects of the 1998 climatic disturbance.

The significant regional variation in coral cover observed in all periods, and the temporal variation in each region contrast with the PSEA data where both coral cover and its rate of decline are more uniform between regions possibly because local causes seem to operate in synchrony on a region-wide scale (Gardner et al. 2003; Bruno and Selig 2007). In contrast, the variation in IO-wide cover remained high even during the period of lowest coral cover after 1998 (Fig. 1; Table 2; ESM Appendix 2). In the IO, the greatest change in mean coral cover occurred between periods 2 and 3, mostly for the reefs that were impacted the most by the 1998 bleaching disturbance (ESM Appendix 2). This is most obvious on reefs in the Central Indian Ocean Islands (CIOI) that had one of the highest coral cover values prior to 1998, but the least after 1998. Reefs in this area now generally have low, or recovering coral cover and a depauperate coral community structure (McClanahan et al. 2007b; Graham et al. 2008).

In general, areas with fisheries closures and other protected areas in the IO suffered larger losses in coral in 1998 than fished reefs (Fig. 6). This has been reported for Kenya (McClanahan et al. 2001; McClanahan 2008), Seychelles (Graham et al. 2007) and a subset of other countries in the region (Graham et al. 2008). Areas closed to fishing could have suffered higher cover loss due to their 
location in environmentally susceptible locations or due to their dominance by more susceptible taxa, as a high initial cover of susceptible corals will inevitably lead to a greater percent loss. A WIO-wide analysis of temperature data and bleaching susceptibility indicated that most of MPAs in the region are located in environmentally susceptible locations (Maina et al. 2008) and a large scale WIO-wide study by McClanahan et al. (2007c) showed that taxonomic composition contributed almost 50\% of the variation in bleaching response.

The lack of a significant difference in period 4 between fished and fisheries closures indicates that absolute recovery has been greater in areas where there is some environmental management although the rate of recovery in fisheries closures varied between regions. For example, Chagos showed very high recovery while Seychelles had less recovery (Graham et al. 2008; Sheppard et al. 2008). Similarly, in Tanzania, reefs in the central part (e.g., Zanzibar) suffered less and recovered faster than those in the northern region (e.g., Mafia Islands) (McClanahan et al. 2007a; Graham et al. 2008; Ateweberhan and McClanahan 2010). In contrast, detailed analyses of coral cover and community structure in Kenya also indicated a lower recovery of managed reefs than fished reefs. In comparison to old parks (closed from fishing in 1968 and 1972), the younger park at Mombasa (closed in 1991) recovered faster (McClanahan et al. 2001; McClanahan 2008). The larger initial impact is associated with the preponderance of bleaching-susceptible taxa in the closures. Fished reefs in Kenya, which tend to be dominated by fleshy and turf algae and have lower coral cover that is 
comprised mostly of bleaching resistant coral taxa, recovered to pre 1998 level within three years after the disturbance (McClanahan 2008).

Other studies in the region have indicated that the response to the 1998 disturbance involved complex interactions between environmental and community structure properties (Obura 2001, 2005; McClanahan and Maina 2003; McClanahan et al. 2005, 2007a, 2007b; Maina et al. 2008; Ateweberhan and McClanahan 2010). The thermal stress in 1998 was strongly correlated with SST variability; reefs with higher SST variability showed lower overall mortality (McClanahan et al. 2007a). Other factors, such as high irradiation, also interact with temperature in strengthening the impacts of thermal stress (Maina et al. 2008) while clouds and oceanic cooling reduce the effects (Obura 2005; Turner and Klaus 2005; Maina et al. 2008). For instance, the relatively low bleaching impact in the Mascarene Islands in 1998 was attributed to the cooling effects of Cyclone Anacelle, which caused high winds, ocean mixing, heavy cloud cover and rainfall during the peak of the thermal event in February 1998 (Turner et al. 2000, Obura 2005). Similarly, heavy rainfall and associated cloud cover and sediment levels could have played a great role in minimizing bleaching impacts on reefs in the Songo Songo Archipelago, central Tanzania (Obura 2005). McClanahan et al. (2007a) reported that the Mascarene region has a relatively higher SST variability in the southern tropical WIO and contested the previous reports (Turner et al. 2000; Obura 2005) as the bleaching impact in 1998 was higher on more exposed offshore sites most influenced by oceanic conditions. 
The temporal change in the relationship between coral cover and latitude/longitude reflects a spatial gradient in environmental variables that influence coral cover change. In East Africa for example, McClanahan et al. (2007a) found a strong negative relationship between latitude and thermal stress, represented by degree heating months, which in turn had a strong negative correlation with sea surface temperature (SST) variability. This finding was strengthened by the study of Maina et al. (2008) that covered a wider area of the WIO, excluding the Arabian region. Ateweberhan and McClanahan (2010) found a U-shaped relationship between degree heating months in 1998, coral cover decline and SST variability. The significant relationship between coral cover and latitude (Ushaped) in the period immediately after 1998 is a reflection of the strong decline in cover in the north-central IO. Similarly, the coverlongitude relationship shows that the central IO region that had the highest cover before 1998 had the lowest cover after 1998.

For a given thermal stress level, reefs dominated by bleaching susceptible branching and encrusting forms, such as Acropora,

Montipora and Pocillopora suffered higher cover losses than those dominated by massive and sub-massive forms, belonging to the Favidae and Poritidae (Obura 2001; McClanahan et al. 2004) and the post 1998 coral community structure reflected the impact of the 1998 event itself (McClanahan et al. 2007b), in that many reefs show a change from Acropora dominance to Poritidae and Favidae dominance (Sheppard et al. 2010). Changes in community structure can therefore be greater than changes in coral cover suggest. 
Since 1998, successive bleaching events have been observed in the region but none had the strength of the 1998 event. Responses to these smaller bleaching events have reflected the effect of the 1998 event itself, owing to the resultant community structure (McClanahan et al. 2007b). Massive and sub-massive forms that were less impacted by post 1998 bleaching events now dominant these reefs. Despite this clear evidence of the influence of community structure in shaping future responses, detailed studies are lacking. Population level studies on how the 1998 disturbance shaped adaptation of coral species populations to climate change were only done for the Arabian Gulf (Sheppard et al. 2010). It is highly likely that the 1998 disturbance will continue to shape future responses. For example, Maynard et al. (2008) found a greater thermal tolerance of Great Barrier Reef corals to a strong bleaching event in 2002 compared with an earlier, weaker one in 1998. Similarly, comparison of bleaching events in the eastern Pacific indicated higher thermal tolerance to the stronger 1998 bleaching event compared with a slightly weaker 1982/83 event (Glynn et al. 2001; Podesta and Glynn 2001).

The 2001-2005 coral cover was directly correlated with the cover immediately after 1998 (Fig. 5). This indicates that coral cover on most of the reefs has not recovered to the level of pre 1998 and the impact was still visible at the end of the study. India-Sri Lanka is an exception, showing the largest recovery of cover; in 2005 it had reached 41.7\% as compared to 39.2\% pre-1998. The Chagos Archipelago also showed large post-bleaching recovery (Sheppard 1999; Sheppard et al. 2008) but this has been masked by the lack of 
recovery in most of the CIOI when pooling data. In general, the IO has shown a much more stepped response, both in decline and subsequent recovery, than was seen in the Caribbean and Pacific regions.

Considering the variability in coral cover within a region and between regions, pooling data is likely to miss variation in coral cover change within specific sub-regions. For example, earlier studies in Tanzania had indicated that responses in 1998 significantly varied within the country. Reefs in Zanzibar and Songo Songo suffered less mortality than those in Mafia or Mtwara (Mohamed et al. 2002; Muhando and Mohammed 2002; Obura 2005; McClanahan et al. 2007a). In Seychelles, the inner granitic islands suffered more mortality than the outer coralline atolls (Spencer et al. 2000; Graham et al. 2006). Similarly, the northern Maldives experienced greater coral mortality than southern Maldives (Ateweberhan and McClanahan 2010). Furthermore, pooling data will miss the difference in response between areas closed and open to fishing associated with local environmental effects that are expected to interact with management (McClanahan et al. 2001; Graham et al. 2008; McClanahan 2008). Given the large local, regional and between region variations inherent to coral reefs, ideally a fairly large number of sites must be monitored to detect ecologically meaningful changes. Our aim was to quantify broad-scale and relatively long-term patterns of coral cover in a less studied, but major coral reef region, and compare these with patterns in other regions, such as the Caribbean and the rest of the Indo-Pacific. 
A region-wide analysis such as this where different data sources are used could be prone to several potential sources of error. One of these has been establishing reliability of data collected by non-experts, such as the Reef Check (Bruno and Selig 2007). Our comparison of Reef Check data with those from other sources indicates over estimation of coral cover in the former (see methods section). The findings are different from those reported in Bruno and Selig (2007) where Reef Check data tend to underestimate cover. It is possible that there was bias in Reef Check data towards high cover reefs in the Eastern Indian Ocean (EIO) where Reef Check data were from in this study, and the large cover in period 4 in that region could have been influenced by the relatively higher representation of Reef Check data during that period (Table 1). The difference with Bruno and Selig (2007) probably reflects the inconsistency in Reef Check data associated with the high turnover in the composition of Reef Check volunteers. Bruno and Selig (2007) attribute the relatively low coral cover in the Reef Check data to the absence of high cover reefs. However, the EIO was among the least impacted in 1998 and remains one of the few IO regions with relatively high coral cover (Fig. 3; Table 2). We also checked if coral cover varied by depth and found that depth had significant but weaker effect in comparison to those associated with region and period (see methods section). This could be due to the fact that most of the locations were relatively shallow ( 231 sites $<5 \mathrm{~m} ; 336$ sites 5-10 m; 60 sites 10-15 m; 10 sites 15-20 m; only 2 Red Sea sites 30 and $40 \mathrm{~m}$ ). We also believe most of the remaining data points were from shallow zones as reported in other Indo-Pacific regions (e.g., Bruno and Selig 2007) and depth would not have influenced the outcome of this analysis in a major way. Finally, independence of sites between two periods could not be ascertained, particularly 
for data from the gray and older peer-reviewed literature. Sites and locations were identified only by names and it was less clear whether the same station was sampled during each period and this source of error could be difficult to eliminate entirely.

In conclusion, filling the information gap on regional change in coral cover is a high priority for taking appropriate management measures in preventing further destruction of coral reefs in the IO region. The general trend in coral cover differs from observations in the wider Caribbean and the Pacific/SE Asia regions where decline in coral cover has been more uniform, started much earlier in the 1980s and was linked with other anthropogenic factors. In contrast, the broad IO wide change was mainly linked with the 1998-

bleaching disturbance and there has been a steady region wide recovery. Areas with fishery closures suffered greater coral cover loss but seem to be recovering at a faster rate. The lack of strong influence of other additional stress factors in the IO in comparison with the Caribbean and Pacific/SE Asia regions and the faster recovery in areas closed to fisheries probably indicate that coral reef resilience to climate change induced disturbance could be enhanced by limiting the influence of other stress factors. The observation 
that some closures recovered faster or slower than others calls for further investigation in order to identify factors that limit or facilitate resilience of coral reefs.

\section{Acknowledgements}

The Wildlife Conservation Society supported this study through a number of sources: the World Bank Targeted Research Group on

Coral Bleaching and Western Indian Ocean Science for Management Program (MASMA). The database is a product of the hard work of many scientists and volunteers who contributed data to 'Reef Check' and published results in peer-reviewed and non-reviewed reports.

\section{References}

Aronson RB, Precht WF (2006) Conservation, precaution, and Caribbean reefs. Coral Reefs 25:441-450

Ateweberhan M, McClanahan TR (2010) Relationship between historical sea-surface temperature variability and climate changeinduced coral mortality in the western Indian Ocean. Mar Pollut Bull 60:964-970

Baker AC, Glynn PW, Riegl B (2008) Climate change and coral reef bleaching: an ecological assessment of the long-term impacts, recovery trends and future outlooks. . Estuar Coast Shelf Sci 80:435-471 
Bell JD, Galzin R (1984) Influence of live coral cover on coral-reef fish communities. Mar Ecol Prog Ser 15:265-274

Bellwood DR, Hughes TP, Folke C, Nystrom M (2004) Confronting the coral reef crisis. Nature 429:827-832

Bruno JF, Selig ER (2007) Regional decline of coral cover in the Indo-Pacific: timing, extent, and subregional comparisons. PLoS One 2:e711

Carleton JH, Done TJ (1995) Quantitative video sampling of coral reef benthos: large-scale application. Coral Reefs 14:35-46

Carpenter KE, Abrar M, Aeby G, Aronson RB, Banks S, Bruckner A, Chiriboga A, Cortes J, Delbeek JC, DeVantier L (2008) Onethird of reef-building corals face elevated extinction risk from climate change and local impacts. Science 321:560-563

Done TJ (1992) Phase shifts in coral reef communities and their ecological significance. Hydrobiologia 247:121-132

Edinger EN, Jompa J, Limmon GV, Widjatmoko W, Risk MJ (1998) Reef degradation and coral biodiversity in Indonesia: effects of land-based pollution, destructive fishing practices and changes over time. Mar Pollut Bull 36:617-630

Gardner TA, Côté IM, Gill JA, Grant A, Watkinson AR (2003) Long-term region-wide declines in Caribbean corals. Science 301:958960

Gardner TA, Côté IM, Gill JA, Grant A, Watkinson AR (2005) Hurricanes and Caribbean coral reefs: impacts, recovery patterns, and role in long-term decline. Ecology 86:174-184

Garpe KC, Yahya SAS, Lindahl U, Ohman MC (2006) Long-term effects of the 1998 coral bleaching event on reef fish assemblages. Mar Ecol Prog Ser 315:237-247 
Glynn PW, Mate JL, Baker AC, Calderon MO (2001) Coral bleaching and mortality in panama and ecuador during the $19971998 \mathrm{El}$ NinoSouthern Oscillation Event: spatial/temporal patterns and comparisons with the 1982-1983 event. Bull Mar Sci 69:79-109

Graham NAJ, Wilson SK, Jennings S, Polunin NVC, Bijoux J, Robinson J (2006) Dynamic fragility of oceanic coral reef ecosystems. Proc Natl Acad Sci USA 103:8425-8429

Graham NAJ, Wilson SK, Jennings S, Polunin NVC, Robinson JAN, Bijoux JP, Daw T (2007) Lag effects in the impacts of mass coral bleaching on coral reef fish, fisheries, and ecosystems. Conserv Biol 21:1291-1300

Graham NAJ, Chabanet P, Evans RD, Jennings S, Letourneur Y, MacNeil MA, McClanahan TR, Öhman MC, Polunin NVC, Wilson SK (2011) Extinction vulnerability of coral reef fishes. Ecol Lett doi: 10.1111/j.1461-0248.2011.01592.x

Graham NAJ, McClanahan TR, MacNeil MA, Wilson SK, Polunin NVC, Jennings S, Chabanet P, Clark S, Spalding MD, Letourneur Y, Bigot L, Galzin R, Öhman MC, Garpe KC, Alasdair JE, Sheppard CRC (2008) Climate warming, Marine Protected Areas and the ocean-scale integrity of coral reef ecosystems. PlosONE 3(8): e3039

Hastings A (1980) Disturbance, coexistence, history, and competition for space. Theor Popul Biol 18: 363-373

Hoegh-Guldberg O (1999) Climate change, coral bleaching and the future of the world's coral reefs. Mar Freshw Res 50:839-866

Hoegh-Guldberg O, Mumby PJ, Hooten AJ, Steneck RS, Greenfield P, Gomez E, Harvell CD, Sale PF, Edwards AJ, Caldeira K

(2007) Coral reefs under rapid climate change and ocean acidification. Science 318:1737-1742

Hughes TP, Ayre D, Connell JH (1992) The evolutionary ecology of corals. Trend Ecol Evol 7: 292-295 
Hughes TP, Graham NAJ, Jackson JBC, Mumby PJ, Steneck RS (2010) Rising to the challenge of sustaining coral reef resilience.

Trends Ecol Evol 25:633-642

Hughes TP, Baird AH, Bellwood DR, Card M, Connolly SR, Folke C, Grosberg R, Hoegh-Guldberg O, Jackson JBC, Kleypas J,

Lough JM, Marshall P, Nystrom M, Palumbi S, Pandolfi JM, Rosen B, Roughgarden J (2003) Climate change, human impacts, and the resilience of coral reefs. Science 301:929-933

Idjadi JA, Edmunds PJ (2006) Scleractinian corals as facilitators for other invertebrates on a Caribbean reef. Mar Ecol Prog Ser319:117-127

Jones GP, McCormick MI, Srinivasan M, Eagle JV (2004) Coral decline threatens fish biodiversity in marine reserves. Proc Natl Acad Sci USA 101:8251-8258

Lindén O, Sporrong N (1999) Coral reef degradation in the Indian Ocean: Status reports and project presentations 1999. CORDIO

Linden O, Souter D, Wilhelmsson D, Obura D (2002) Coral reef degradation in the Indian Ocean: status report 2002

http://cmsdata.iucn.org/downloads/cordio_status_report_2002.pdf

Maina J, Venus V, McClanahan TR, Ateweberhan M (2008) Modelling susceptibility of coral reefs to environmental stress using remote sensing data and GIS models. Ecol Model 212:180-199

Maynard JA, Anthony KRN, Marshall PA, Masiri I (2008) Major bleaching events can lead to increased thermal tolerance in corals.

Mar Biol 155:173-182 
McClanahan TR (2008) Response of the coral reef benthos and herbivory to fishery closure management and the 1998 ENSO disturbance. Oecologia 155:169-177

McClanahan TR, Maina J (2003) Response of coral assemblages to the interaction between natural temperature variation and rare warm-water events. Ecosystems 6:551-563

McClanahan T, Muthiga N, Mangi S (2001) Coral and algal changes after the 1998 coral bleaching: interaction with reef management and herbivores on Kenyan reefs. Coral Reefs 19:380-391

McClanahan T, Polunin N, Done T (2002) Ecological states and the resilience of coral reefs. Conserv Ecol 6:18

McClanahan TR, Baird AH, Marshall PA, Toscano MA (2004) Comparing bleaching and mortality responses of hard corals between southern Kenya and the Great Barrier Reef, Australia. Mar Pollut Bull 48:327-335

McClanahan TR, Maina J, Moothien Pillay R, Baker AC (2005) Effects of geography, taxa, water flow, and temperature variation on coral bleaching intensity in Mauritius. Mar Ecol Prog Ser 298:131-142

McClanahan TR, Ateweberhan M, Muhando C, Maina J, Mohammed SM (2007a) Effects of climate and seawater temperature variation on coral bleaching and mortality. Ecol Monogr 77:503-525

McClanahan TR, Ateweberhan M, Sebastian CR, Graham NAJ, Wilson SK, Bruggemann H, Guillaume M (2007b) Western Indian Ocean coral communities, bleaching responses, and susceptibility to extinction. Mar Ecol Prog Ser 337:1-13 
McClanahan TR, Ateweberhan M, Ruiz Sebastian C, Graham NAJ, Wilson SK, Bruggemann JH, Guillaume MMM (2007c)

Predictability of coral bleaching from synoptic satellite and in situ temperature observations. Coral Reefs 26:695-701

Mohamed SM, Muhando C, Machano H (2002) Assessment of coral reef degradation in Tanzania; Results of Coral Reef Monitoring 1999-2002. In: Linden O, Souter D, Wilhelmsson D, Obura D (eds) Coral reef degradation in the Indian Ocean, status report 2002. CORDIO, Kalmar, Sweden, pp21-30

Muhando CA, Mohammed MS (2002) Coral reef benthos and fisheries in Tanzania before and after the 1998 bleaching and mortality event. Western Indian Ocean. J Mar Sci 1: 43-52,

Mumby PJ, Hastings A, Edwards HJ (2007) Thresholds and the resilience of Caribbean coral reefs. Nature 450:98-101

Norström AV, Nyström M, Lokrantz J, Folke C (2008) Alternative states on coral reefs: beyond coral-macroalgal phase shifts. Mar Ecol Prog Ser 376:295-306

Nyström M, Folke C, Moberg F (2000) Coral reef disturbance and resilience in a human-dominated environment. Trends Ecol Evol $15: 413-417$

Obura DO (2001) Can differential bleaching and mortality among coral species offer useful indicators for assessment and management of reefs under stress? Bull Mar Sci 69:421-442

Obura DO (2005) Resilience and climate change: lessons from coral reefs and bleaching in Western Indian Ocean. Estuar Coast Shelf Sci 63:353-372 
Podesta GP, Glynn PW (2001) The 1997-98 El Nino event in Panama and Galapagos: an update of thermal stress indices relative to coral bleaching. Bull Mar Sci 69:43-59

Pratchett MS, Munday PL, Wilson SK, Graham NAJ, Cinner JE, Bellwood DR, Jones GP, Polunin NVC, McClanahan TR (2008)

Effects of climate-induced coral bleaching on coral-reef fishes- ecological and economic consequences. Oceanogr Mar Biol Annu Rev 46:251-296

Sandin SA, Smith JE, DeMartini EE, Dinsdale EA, Donner SD, Friedlander AM, Konotchick T, Malay M, Maragos JE, Obura D, Pantos O, Paulay G, Richie M, Rohwer F, Schroeder RE, Walsh S, Jackson JBC, Knowlton N, Sala E (2008) Baselines and degradation of coral reefs in the northern Line Islands. PLoS ONE 3:e1548

Scheer G (1974) Investigation of coral reefs at Rasdu Atoll in the Maldives with the quadrat method according to phytosociology. Proc $2^{\text {nd }}$ Coral Reef Symp 2:655-670

Schutte V, Selig ER, Bruno JF (2010) Regional spatio-temporal trends in Caribbean coral reef benthic communities. Mar Ecol Prog Ser 402:115-122.

Selig ER, Bruno JF (2010) A global analysis of the effectiveness of Marine Protected Areas in preventing coral loss. PLoS One 5:e9278 
Sheppard C, Al-Husiani M, Al-Jamali F, Al-Yamani F, Baldwin R, Bishop J, Benzoni F, Dutrieux E, Dulvy NK, Durvasula SRV, Jones DA, Loughland R, Medio D, Nithyanandan M, Pillingm GM, Polikarpov I, Price ARG, Purkis S, Riegl B, Saburova M, Namin KS, Taylor O, Simon Wilson d KZ (2010) The Gulf: A young sea in decline. Mar Pollut Bull 60:13-38

Sheppard CRC (1999) Changes in coral cover on reefs of Chagos over eighteen years. In: Sheppard CRC, Seaward MRD (eds)

Ecology of the Chagos Archipelago. Westbury Publishing, Great Britain, pp91-100

Sheppard CRC (2003) Predicted recurrences of mass coral mortality in the Indian Ocean. Nature 425:294-297

Sheppard CRC, Harris A, Sheppard ALS (2008) Archipelago-wide coral recovery patterns since 1998 in the Chagos Archipelago, central Indian Ocean. Mar Ecol Prog Ser 362:109-117

Souter D, Linden O (eds) (2005) Coral reef degradation in the Indian Ocean. Status report 2005. CORDIO, Univ. of Kalmar, Sweden Souter D, Obura D, Lindén O (2000) Coral reef degradation in the Indian Ocean. Status report 2000. CORDIO, SAREC Marine Science Program, Stockholm, Sweden

Spencer T, Teleki KA, Bradshaw C, Spalding MD (2000) Coral bleaching in the southern Seychelles during the 1997-1998 Indian Ocean warm event. Mar Pollut Bull 40:569-586

Sweatman H, Delean S, Syms S ( 2011) Assessing loss of coral cover on Australia's Great Barrier Reef over two decades, with implications for longer-term trends. Coral Reefs: DOI: 10.1007/s00338-010-0715-1 
Turner J, Klaus R (2005) Coral reefs of the Mascarenes, Western Indian Ocean. Philos Trans

R Soc Lond A 363:229-250

Turner, J, Hardman E, Klaus R, Fagoonee I, Daby D, Baghooli R, Persands S (2000) The reefs of Mauritius. In: Souter D, Obura D,

Lindén O (eds) Coral reef degradation in the Indian Ocean. Status report 2000. CORDIO, SAREC Marine Science Program, Stockholm, Sweden

Wilkinson C (2002) Status of coral reefs of the world: 2002. Australian Institute of Marine Science, Townsville

Wilkinson C (2004) Status of coral reefs of the world: 2004. Australian Inst. of Marine Science, Townsville

Wilkinson CR (1999) Global and local threats to coral reef functioning and existence: review and predictions. Mar Freshw Res $50: 867-878$

Wilson SK, Graham NAJ, Polunin NVC (2007) Appraisal of visual assessments of habitat complexity and benthic composition on coral reefs. Mar Biol 151:1069-1076

Table 1. Number of samples by data type, management and region for the four periods. Period 1: 1977-1993; Period 2: 1994-1997;

Period 3: 1999-2000; Period 4: 2001-2005. 


\begin{tabular}{|c|c|c|c|c|}
\hline Data type & Period 1 & Period 2 & Period 3 & Period 4 \\
\hline Peer reviewed & 105 & 122 & 121 & 102 \\
\hline Gray literature & 24 & 149 & 246 & 278 \\
\hline Reef Check & 0 & 136 & 91 & 439 \\
\hline Unpublished surveys & 16 & 27 & 18 & 116 \\
\hline Total & 154 & 434 & 476 & 935 \\
\hline \multicolumn{5}{|l|}{ By management for the four periods } \\
\hline Fished & 7 & 31 & 28 & 38 \\
\hline Fisheries closures & 16 & 52 & 55 & 77 \\
\hline Total & 23 & 83 & 83 & 115 \\
\hline \multicolumn{5}{|l|}{ By region for the four periods } \\
\hline Arabian Sea (ARABS) & 0 & 13 & 10 & 10 \\
\hline Western Australia (AUSW) & 0 & 2 & 2 & 43 \\
\hline Bay of Bengal (BBENG) & 0 & 1 & 1 & 1 \\
\hline Central Western Indian Ocean Islands (CIOI) & 29 & 141 & 143 & 174 \\
\hline East Africa (EAFR) & 18 & 67 & 62 & 80 \\
\hline
\end{tabular}




\begin{tabular}{|c|c|c|c|c|}
\hline Eastern Indian Ocean (EIO) & 38 & 19 & 36 & 187 \\
\hline Arabian/Persian Gulf (GULF) & 4 & 28 & 37 & 22 \\
\hline India \& Sri Lanka (IND-SRI) & 0 & 27 & 22 & 42 \\
\hline Mozambique \& South Africa (MOZ-SAF) & 2 & 16 & 25 & 41 \\
\hline Red Sea \& Gulf of Aden (RS-GA) & 37 & 81 & 36 & 150 \\
\hline South Western Indian Ocean Islands (SWIOI) & 3 & 39 & 102 & 185 \\
\hline Total IO & 131 & 434 & 476 & 935 \\
\hline
\end{tabular}

Regions: Arabian Sea (ARABS), Western Australia (AUSW: Scott Reef, Cocos-Keeling Islands, Christmas Island), Bay of Bengal (BBENG: Bangladesh), Central Indian Ocean

Islands (CIOI: Chagos, Lakshadweep, Maldives, Seychelles), East Africa (EAFR: Kenya, Tanzania), Eastern Indian Ocean (EIO: Andaman-Nicobar, Western Indonesia (Sumatra), Kambodia, Myanmar/Burma, Thailand), Arabian/Persian Gulf (GULF), Southern India and Sri Lanka (IND-SRI), Mozambique and South Africa (MOZ-SAF), Red Sea-Gulf of Aden (RS-GA), South Western Indian Ocean Islands (SWIOI: Comoros, Madagascar, Mauritius, Mayotte, Reunion, Rodrigues). Regions with small sample sizes (N < 20) were excluded from the analyses. Data before 1977 (22 peer reviewed and 2 gray literature) were not included in any of the analysis as they were based only on a single study (Scheer 1974) and mostly from one area (Central Maldives, CIOI) 
Table 2. Summary of Repeated Measures ANOVA (RMA) on temporal variation in regional coral cover and its interaction with region, latitude and longitude. Multivariate and univariate analysis results are given. Unadj: Unadjusted; G-G: Green House-Gesser;

H-F Test: Huynh-Feldt Test.

\section{Sphericity Test}

Mauchly

$\begin{array}{llll}\text { Criterion } & \text { ChiSquare } & \text { DF } & \text { P } \\ 0.31 & 7.95 & 5.00 & 0.16\end{array}$

Period

$\begin{array}{llll} & \text { Unadj } & \text { G-G } & \text { H-F } \\ \text { F } & 7.27 & 5.00 & 5.00 \\ \text { NumDF } & 3.00 & 3.00 & 1.71 \\ \text { DenDF } & 6.00 & 24.00 & 13.69 \\ \text { p } & 0.02 & 0.01 & 0.03\end{array}$

\section{Region*Period}




$\begin{array}{llll}\text { NumDF } & 5.00 & 15.00 & 8.55 \\ \text { DenDF } & 8.00 & 24.00 & 13.69 \\ \mathrm{p} & 0.0003 & 0.0005 & 0.0069\end{array}$

\section{Latitude*Period}

\begin{tabular}{|c|c|c|c|}
\hline $\mathrm{F}$ & 2.18 & 3.36 & 3.36 \\
\hline NumDF & 3.00 & 3.00 & 1.71 \\
\hline DenDF & 6.00 & 24.00 & 13.69 \\
\hline $\mathrm{p}$ & 0.19 & 0.04 & 0.07 \\
\hline \multicolumn{4}{|c|}{ Longitude*Period } \\
\hline $\mathrm{F}$ & 6.395 & 4.405 & 4.405 \\
\hline NumDF & 3.000 & 3.000 & 1.711 \\
\hline DenDF & 6.000 & 24.000 & 13.686 \\
\hline $\mathrm{p}$ & 0.027 & 0.013 & 0.038 \\
\hline
\end{tabular}


Table 3. Summary statistics of the regional coral cover data for the four major periods. Region names and abbreviations as in Table 1. ND: no data available. No statistical comparisons were made for regions with small sample sizes $(\mathrm{N}<20)$. Data prior to 1977 not presented (see Table 1). See Table 1 for region and country names.

\begin{tabular}{ccccccccc} 
Region & Period & Mean & Median & Min & Max & SD & Skewness & Kurtosis \\
\hline \multicolumn{2}{c}{ A. WIO wide coral cover } & & & & & & & \\
\hline
\end{tabular}

B. Regional coral cover

\begin{tabular}{llllllllll} 
AUSW & 4 & 33.87 & 29.38 & 0.63 & 71.25 & 24.01 & 0.16 & -1.62 & 43 \\
\hline CIOI & 1 & 53.04 & 50.00 & 7.00 & 100.00 & 26.38 & 0.11 & -0.75 & 29 \\
& 2 & 40.20 & 38.63 & 9.38 & 90.00 & 18.03 & 0.60 & -0.04 & 141
\end{tabular}




\begin{tabular}{|c|c|c|c|c|c|c|c|c|c|}
\hline & 3 & 6.93 & 5.00 & 0.00 & 31.90 & 6.87 & 1.59 & 2.25 & 143 \\
\hline & 4 & 12.66 & 7.27 & 0.00 & 74.00 & 14.46 & 2.09 & 4.62 & 174 \\
\hline \multirow[t]{3}{*}{ EAFR } & 2 & 34.55 & 37.00 & 1.25 & 77.77 & 19.04 & 0.18 & -0.59 & 67 \\
\hline & 3 & 19.75 & 15.70 & 1.00 & 59.00 & 15.04 & 0.87 & -0.01 & 62 \\
\hline & 4 & 29.17 & 22.16 & 1.88 & 81.25 & 20.22 & 1.08 & 0.18 & 80 \\
\hline \multirow[t]{3}{*}{ EIO } & 1 & 31.66 & 29.15 & 5.00 & 76.00 & 18.73 & 0.45 & -0.47 & 38 \\
\hline & 3 & 34.57 & 33.53 & 8.10 & 73.13 & 16.73 & 0.56 & -0.24 & 36 \\
\hline & 4 & 42.00 & 41.88 & 0.63 & 85.34 & 19.73 & 0.10 & -0.90 & 187 \\
\hline \multirow[t]{3}{*}{ GULF } & 2 & 55.60 & 51.00 & 16.00 & 97.00 & 24.76 & 0.31 & -1.22 & 28 \\
\hline & 3 & 20.08 & 16.00 & 0.00 & 85.00 & 20.75 & 1.37 & 2.03 & 37 \\
\hline & 4 & 32.92 & 26.50 & 20.00 & 62.50 & 16.11 & 1.59 & 2.21 & 22 \\
\hline \multirow[t]{3}{*}{ IND-SRI } & 2 & 44.71 & 40.00 & 11.70 & 92.00 & 21.32 & 0.52 & -0.44 & 27 \\
\hline & 3 & 12.54 & 5.05 & 0.00 & 51.30 & 16.59 & 1.37 & 0.78 & 22 \\
\hline & 4 & 37.02 & 37.87 & 12.00 & 74.25 & 18.41 & 0.43 & -0.61 & 42 \\
\hline MOZ-SAF & 2 & 31.97 & 32.50 & 13.74 & 52.10 & 15.22 & -0.01 & -1.81 & 16 \\
\hline
\end{tabular}




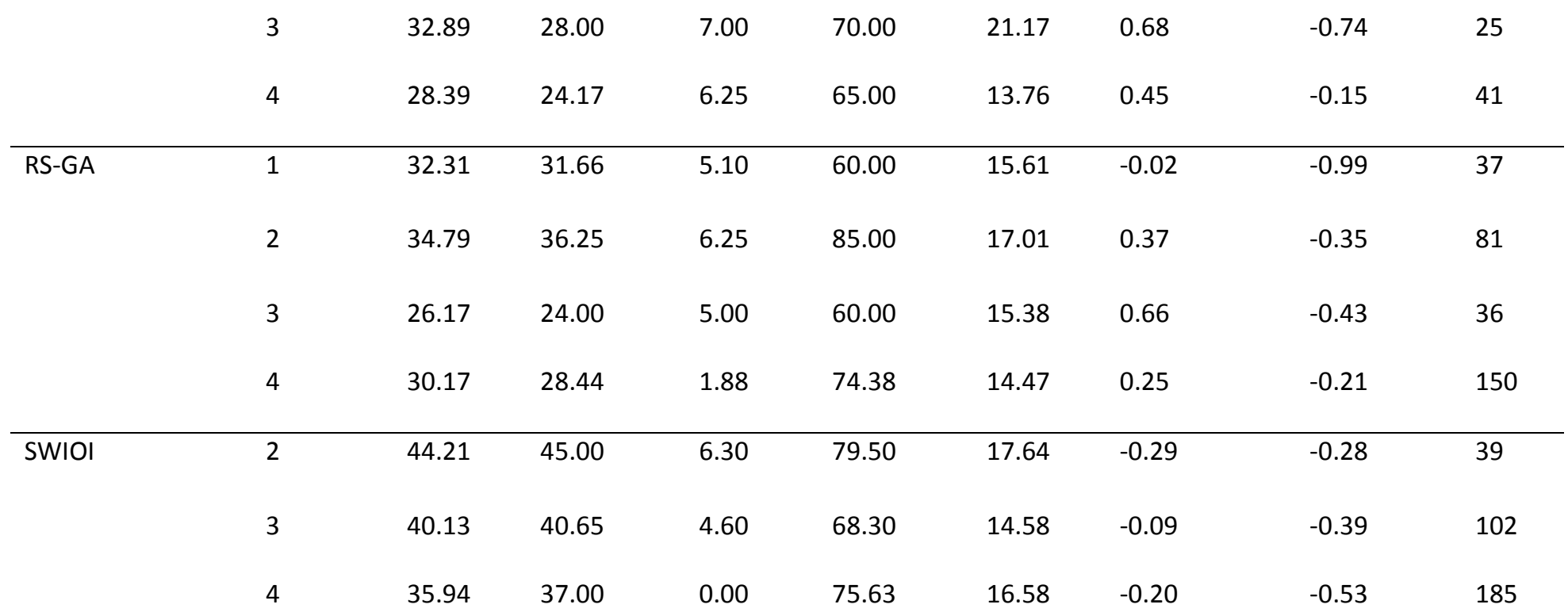


Table 4. Summary of regression analysis for relationships between coral cover and latitude and longitude. Statistically significant $p$ values indicated in bold font and best-fit equations included for these tests.

A. Latitude

\begin{tabular}{lllll}
\hline Period & $\mathrm{R}_{\text {adj }}^{2}$ & ANOVA F & $\mathrm{p}$ & Equation \\
\hline $1977-1993$ & 0 & 0.03 & 0.86 & \\
$1994-1997$ & 0.002 & 0.16 & 0.32 & \\
$1999-2000$ & 0.17 & 4.54 & $<\mathbf{0 . 0 0 0 1}$ & $\mathrm{y}=-0.42 \mathrm{x}+0.02 \mathrm{x}^{2}+17.55$ \\
$2001-2005$ & 0.003 & 2.37 & 0.09 & \\
B. Longitude & & & & \\
\hline $1977-1993$ & 0.12 & 7.60 & $\mathbf{0 . 0 0 0 9}$ & $\mathrm{y}=0.25 \mathrm{x}-0.01 \mathrm{x}^{2}+29.76$ \\
$1994-1997$ & 0.03 & 6.98 & $\mathbf{0 . 0 0 1}$ & $\mathrm{y}=0.22 \mathrm{x}-0.007 \mathrm{x}^{2}+29.76$ \\
$1999-2000$ & 0.12 & 28.33 & $<\mathbf{0 . 0 0 0 1}$ & $\mathrm{y}=-0.36 \mathrm{x}+0.02 \mathrm{x}^{2}+38.24$ \\
$2001-2005$ & 0.08 & 37.06 & $<\mathbf{0 . 0 0 0 1}$ & $\mathrm{y}=0.002 \mathrm{x}+0.01 \mathrm{x}^{2}+24.30$
\end{tabular}




\section{Figure legends}

Fig. 1. The study area in the Indian Ocean (IO). Reef sites with geographic position provided indicated. The 11 regions were designated based on traditional classification and investigator experience. Site 3 (Bay of Bengal) not included in the analysis due to small sample size in all periods (See Methods section). Regions are: Arabian Sea (ARABS), Western Australia (AUSW: Scott Reef, Cocos-Keeling Islands, Christmas Island), Bay of Bengal (BBENG: Bangladesh), Central Indian Ocean Islands (CIOI: Chagos,

Lakshadweep, Maldives, Seychelles), East Africa (EAFR: Kenya, Tanzania), Eastern Indian Ocean (EIO: Andaman-Nicobar, Western Indonesia (Sumatra), Kambodia, Myanmar/Burma, Thailand), Arabian/Persian Gulf (GULF), Southern India and Sri Lanka (INDSRI), Mozambique and South Africa (MOZ-SAF), Red Sea-Gulf of Aden (RS-GA), South Western Indian Ocean Islands (SWIOI: Comoros, Madagascar, Mauritius, Mayotte, Reunion, Rodrigues). Regions with small sample sizes $(\mathrm{N}<20)$ were excluded from the analyses. Data before 1977 (22 peer reviewed and 2 gray literature) were not included in any of the analysis as they were based only on a single study (Scheer 1974) and mostly from one area (Central Maldives, CIOI).

Fig. 2. Temporal change in IO wide coral cover. A. By year change in IO wide coral cover. B. Periodic change in IO wide coral cover. Period 1: 1977-1993 (sparse data and time well before the 1998 mass bleaching event); Period 2: 1994-1997 (time before the 1998 
mass bleaching event); Period 3: 1999-2000 (time immediately after the 1998 bleaching disturbance); Period 4: 2001-2005 (post bleaching recovery period). Box: 25-75\% percentiles; Horizontal bars: 2.5\%, median (50\%), 97.5\% percentiles. Years before 1977 not presented due to small sample size and low regional representation. See Table 1 for sample sizes during each period.

Fig. 3. Periodic change in coral cover in the main IO coral reef regions. See Table 1 and Fig. 2 for description of four periods. Box: 25-75\% percentiles; Horizontal bars: $2.5 \%$, median, $97.5 \%$ percentiles. The 10 regions were designated based on traditional classification and experience (See Methods section and Fig. 1). See Table 1 for sample sizes during each period.

Fig. 4. Relationship between coral cover in period 3 and period 4. IND-SRI is an outlier and the relationship becomes significant after excluding it from the analysis. ARABS and AUS-W not included in the analysis due to small sample size in either of the periods.

Fig. 5. Relationship between coral cover and latitude and cover and longitude for the four periods. Fit lines presented for significant relationships only. Sites within the 10 major IO reef regions indicated. Sites with geographic positions not indicated, were not included in the analysis. 
Fig. 6. Comparison of coral cover between fished and protected reefs for the four periods. See Table 1 for sample sizes during each period. 
Fig. 1

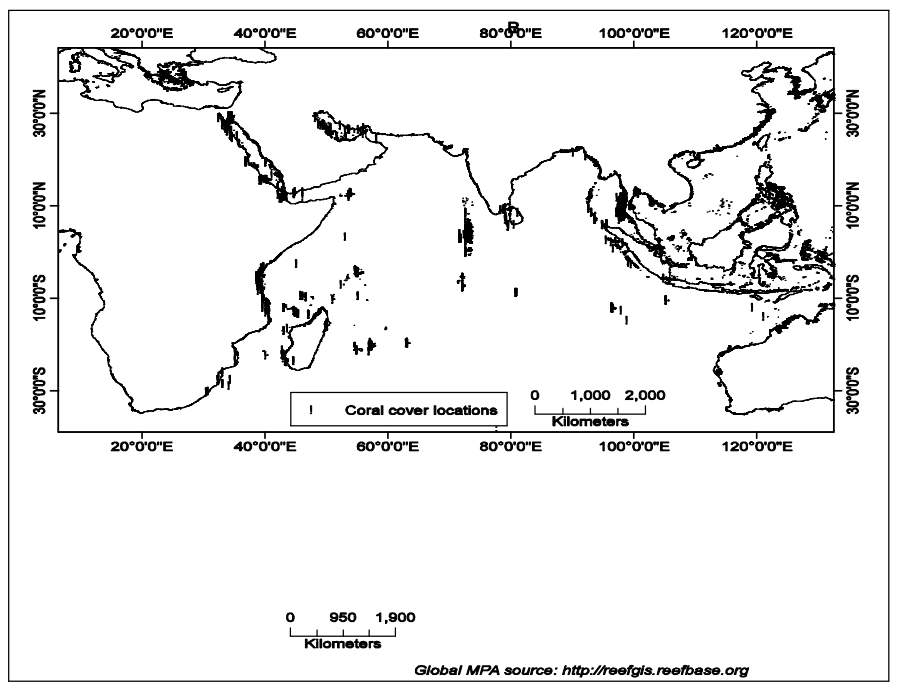


Fig. 2

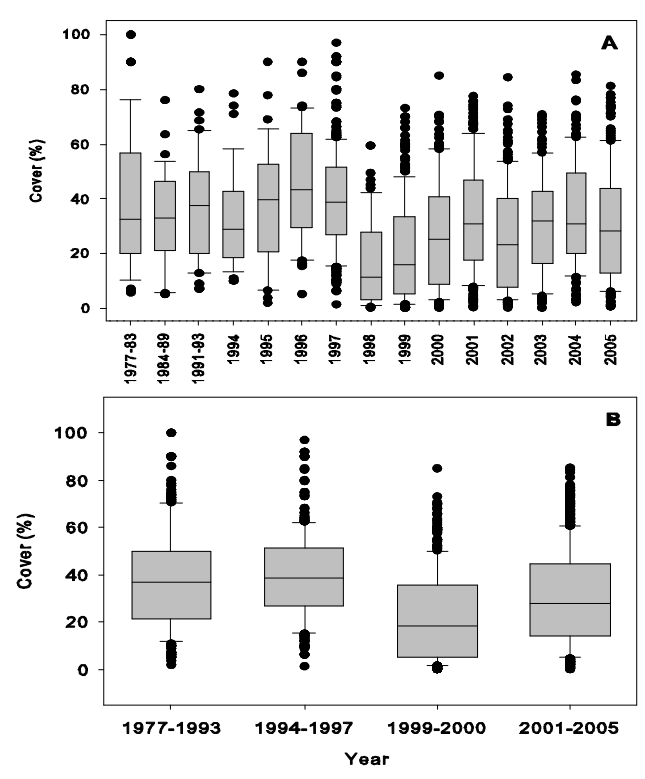


Fig. 3

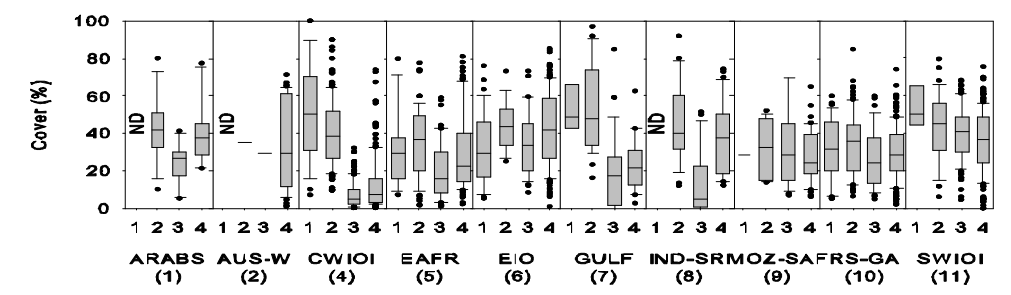

Fig. 4 


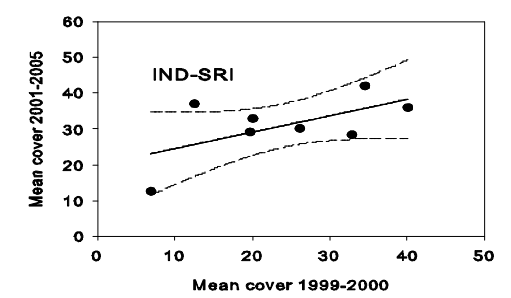


Fig. 5

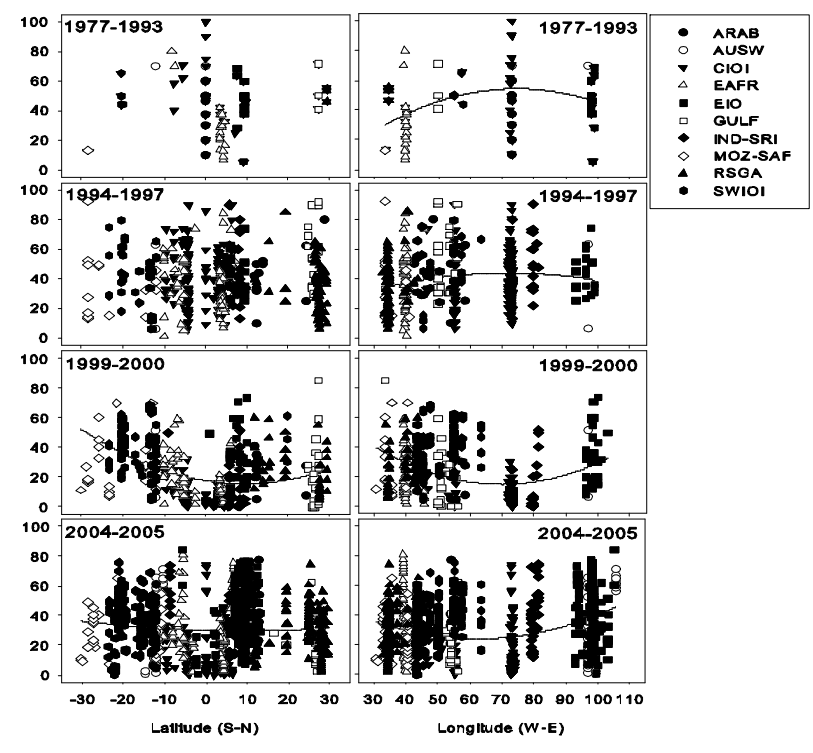


Fig. 6

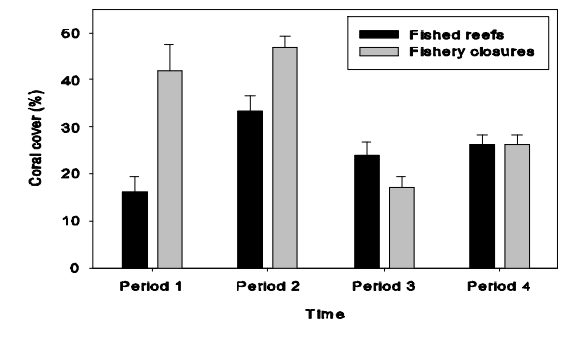

